\title{
Inertia in physiological traits: Embryonopsis halticella caterpillars (Yponomeutidae) across the Antarctic Polar Frontal Zone
}

\author{
C.J. Klok, S.L. Chown* \\ Spatial, Physiological and Conservation Ecology Group, Department of Botany \& Zoology, University of Stellenbosch, Private Bag X1, \\ Matieland 7602, South Africa
}

Received 15 July 2004; received in revised form 16 November 2004; accepted 19 November 2004

\begin{abstract}
Geographic variation is characteristic of many physiological traits at the population and species levels. However, several recent studies have suggested that population-level variation is either limited or that it is mostly a consequence of phenotypic plasticity. Here we show that there is considerable physiological inertia in cold hardiness, upper thermal tolerance limits and desiccation resistance in caterpillars of the sub-Antarctic moth Embryonopsis halticella Eaton, such that populations from two climatically different islands are physiologically very similar. Both populations are moderately chill tolerant, with no difference in the supercooling points of caterpillars $\left(-17\right.$ to $\left.-20^{\circ} \mathrm{C}\right)$. Within their host plants caterpillars of both populations freeze at substantially higher, and statistically equivalent temperatures $\left(-9.5\right.$ to $\left.-11.5^{\circ} \mathrm{C}\right)$. The populations also have similar upper lethal limits $\left(38^{\circ} \mathrm{C}\right)$, and survival times of dry conditions $(6-170 \mathrm{~h}$ depending on mass). The previously inexplicably low freezing point of caterpillars at the climatically less severe Marion Island seems likely a consequence of physiological inertia given that the freezing point of caterpillars within their hosts is only a few degrees below absolute minima at the older, and colder, Heard Island. Lack of adaptive geographic variation in physiological traits has consequences for models of range limits, and highlights the importance of exploring phenotypic plasticity as a response to climatic variation.
\end{abstract}

(C) 2005 Elsevier Ltd. All rights reserved.

Keywords: Acclimation; Cold hardiness; Desiccation resistance; Thermal tolerance

\section{Introduction}

Geographic variation is a hallmark of environmental physiology. Most physiological traits display substantial variation between species and/or populations living in different areas (Spicer and Gaston, 1999), and such patterns have often been used as a basis for arguments in favour of the adaptive nature of physiological variation (see Bartholomew, 1987). In insects, geographic variation has been recorded for a wide variety of physiological traits between populations and species at several spatial scales, ranging from the microgeographic to the macrophysiological (Chown et al., 2004). These traits include metabolic rate (Massion, 1983; Schultz et al.,

\footnotetext{
${ }^{*}$ Corresponding author. Tel.: + 27218082995 ; fax: + 27218082405

E-mail address: slchown@sun.ac.za (S.L. Chown).
}

1992; Addo-Bediako et al., 2002), water balance characteristics (Juliano, 1986; Hoffmann and Parsons, 1989; Gibbs et al., 1991), cold hardiness and low temperature tolerance (Parsons, 1977; Gibert and Huey, 2001; Williams et al., 2002; Sinclair et al., 2003), hightemperature tolerance (Addo-Bediako et al., 2000; Hoffmann et al., 2002), and development rate (Honêk, 1996). Such geographic variation has also routinely been documented for insects of the sub-Antarctic islands. Substantial differences have been reported between species and populations, both across islands which differ substantially in climate, and across altitudes on particular islands, in metabolic rates (Chown, 1997; Chown et al., 1997; Todd, 1997), thermal tolerances (Worland et al., 1992; van der Merwe et al., 1997), and water balance characteristics (Todd and Block, 1997; Chown and Klok, 2003). One of the most detailed 
studies to have made a thorough statistical comparison of variation within and among islands compared the critical thermal minima and maxima (temperatures of cold stupor and heat coma, respectively) of ten species and 31 populations from Marion and Heard Islands (Klok and Chown, 2003). Here, a small portion of the variation in critical thermal limits was found between species, and c. $22 \%$ of the variation was found between islands, which differ substantially in climate because of their position on either side of the Antarctic Polar Frontal Zone. These studies reconfirm the fact that geographic variation in physiological traits is as much a feature of insects as it is of other animals.

Despite the apparent ubiquity of geographic variation in physiological traits, not all species show such variation, and there are considerable differences between traits in the extent to which they vary geographically. In the former case, Hoffmann et al. (2001) examined variance partitioning of desiccation, starvation and cold resistance, body size and lipid content in Drosophila melanogaster among regions, populations, and strains in Australia. Differences between regions and populations accounted for only $0-28 \%$ of the variance in these traits, with strain and individual (including error) differences accounting for the bulk of the variance (71-97\%). Similarly, despite the among species and among island differences, Klok and Chown (2003) also found that most of the variance in critical temperatures was explained by acclimation effects or by among individual (including error) differences $(60-75 \%)$. Likewise, as far as differences between traits are concerned, it has long been appreciated that upper thermal limits tend to be less variable geographically and less responsive to acclimation than lower ones (see Kingsolver and Huey, 1998; Chown, 2001 for review and Hoffmann et al. (2002) for an alternative view).

Nonetheless, the prevalence of limited geographic variation in physiological traits, or physiological inertia (see Huey et al., 2003), is not clear. There are two reasons why this might be the case. First, much of the work on geographic variation in physiological traits has been done within a strong adaptationist framework (reviews in Bartholomew, 1987; Spicer and Gaston, 1999). Whilst the importance of evolution as a theme underlying all of biology means there are good reasons why this should be the case, this approach is also likely to lead an under-reporting of non-significant results, except perhaps where specific hypotheses (such as that of metabolic cold adaptation) are being tested (e.g. Nylund, 1991). This is a classic file-drawer problem (Csada et al., 1996). Second, the extent to which acclimatization might account for such geographic or interspecific variation, especially at the population level, is not widely explored, with the exception perhaps of studies of Drosophila (e.g. Watson and Hoffmann, 1996; Berrigan and Hoffmann, 1998; Hoffmann et al., 2001,
2005; Ayrinhac et al., 2004; but see also Gibbs et al., 1991). Thus, apparently adaptive variation might rather be a consequence of phenotypic plasticity. Here we address both issues by comparing thermal tolerance and desiccation resistance of caterpillars of the sub-Antarctic moth, Embryonopsis halticella (Yponomeutidae) from Marion and Heard Islands. These two islands are widely separated and have very different climates as a consequence of the fact that Marion Island lies to the north, and Heard Island to the south of a major climatic boundary in the Southern Ocean: the Antarctic Polar Frontal Zone (APFZ) (see Knox, 1994; Klok and Chown, 2003). Nonetheless, initial data suggested that the populations of the moth species differ only slightly in several of their physiological characterstics.

\section{Materials and methods}

\subsection{Study animal and study sites}

E. halticella Eaton is a flightless moth endemic to the South Indian Ocean Province Islands (Prince Edward Islands, Crozet archipelago, Kerguelen Islands, Heard Island) of the Southern Ocean (Crafford and Scholtz, 1986). Its larvae feed almost exclusively on the grass Poa cookii, with which they have an intimate association, starting as leaf miners in the early instars and later becoming concealed feeders (sensu Gaston et al., 1991). The species is most abundant in highly manured areas, and at Marion Island has a life cycle of approximately 1 year with overlapping generations (Crafford and Scholtz, 1986).

The climate on Marion Island $\left(46^{\circ} 54^{\prime} \mathrm{S}, 37^{\circ} 45^{\prime} \mathrm{E}\right.$, $1230 \mathrm{~m}$ at its highest point) is cool, wet and windy with little seasonal temperature variation (monthly mean Stevenson Screen values vary between $2{ }^{\circ} \mathrm{C}$ and $7{ }^{\circ} \mathrm{C}$ over the year with a mean of approximately $5^{\circ} \mathrm{C}$ ), though mean annual temperatures have increased by slightly more than $1{ }^{\circ} \mathrm{C}$ over the past 50 years (Schulze, 1971; Smith, 2002). Microclimate (soil surface) temperatures are lower, with absolute temperatures varying between -4.8 and $29.2^{\circ} \mathrm{C}$, and a mean of $5.7^{\circ} \mathrm{C}$ at $25 \mathrm{~m}$ above sea level (over a full year, data provided in Table 1 of Klok and Chown, 1998). Temperatures within Poa cookii tussocks and tillers are generally higher (in autumn, tussock: minimum $-0.5^{\circ} \mathrm{C}$ and maximum $12.5^{\circ} \mathrm{C}$; in summer tiller: minimum $-1.2{ }^{\circ} \mathrm{C}$ and maximum $33.8^{\circ} \mathrm{C}$ ) (Klok and Chown, 1998) (see also Table 1). Heard Island $\left(53^{\circ} 06^{\prime} \mathrm{S}, 73^{\circ} 30^{\prime} \mathrm{E}\right)$ lies south of the APFZ and rises to $2745 \mathrm{~m}$ a.s.l. It is approximately $80 \%$ glaciated, and, as a consequence of its southerly position has a much colder and more seasonal climate than Marion Island. An Argos transmitting automatic weather station showed that between 1997 and 2002 mean annual temperature at Atlas Cove was $2.0^{\circ} \mathrm{C}$, with an 
Table 1

Microclimate measurements in Poa cookii stands on Marion Island (from Klok and Chown, 1998) and Heard Island (October-December 2000)

\begin{tabular}{|c|c|c|c|c|c|}
\hline Temperatures $\left({ }^{\circ} \mathrm{C}\right)$ & Mean & Mean daily min. & Mean daily max. & Absolute min. & Absolute max. \\
\hline \multicolumn{6}{|c|}{ Marion Island, Trypot Beach area, $P$. cookii stand surrounding an albatross nest } \\
\hline Summer data ${ }^{\mathrm{a}}$ & 9.4 & 1.5 & 21.7 & -0.2 & 33.8 \\
\hline \multicolumn{6}{|l|}{ May 1997} \\
\hline Air at $30 \mathrm{~cm}$ & 6.3 & 2.4 & 11.0 & -2.0 & 14.5 \\
\hline Within tussock & 6.1 & 2.9 & 9.6 & -0.5 & 12.5 \\
\hline Within tiller & 6.0 & 2.5 & 10.1 & -1.2 & 12.9 \\
\hline \multicolumn{6}{|c|}{ Heard Island-Atlas Cove, mixed P. cookii/Pringlea antiscorbutica stand, Mt. Aubert de la Rue } \\
\hline Air & & & & -5.9 & 17.2 \\
\hline \multicolumn{6}{|c|}{ Heard Island-Spit Bay } \\
\hline Air & & & & -5.9 & 18.1 \\
\hline
\end{tabular}

${ }^{\text {a }}$ Summer temperature data were extracted from Chown and Crafford (1992) from temperatures measured inside the bases of $P$. cookii tillers from November 1987 to March 1988.

absolute minimum of $-7.6^{\circ} \mathrm{C}$ and an absolute maximum of $15.8^{\circ} \mathrm{C}$. Although tiller temperatures have not been measured at Heard Island, microclimate temperatures within mixed $P$. cookii/Pringlea antiscorbutica stands indicate temperatures varying between $-5.9^{\circ} \mathrm{C}$ and $18.1{ }^{\circ} \mathrm{C}$ over the summer months (Table 1). Collection and laboratory protocols for caterpillars at Marion Island are described fully in Klok and Chown (1998).

Facilities at the field camp at Atlas Cove on Heard Island were basic. Here, host tillers were collected during mid-summer (December 2000-February 2001) from around the Atlas Cove camp or from mixed $P$. cookii/P. antiscorbutica stands at Mt. Aubert de la Rue and returned to the makeshift laboratory within an hour of collection. The same protocols as those used on Marion Island were followed to obtain caterpillars and caterpillars within tillers. These were subsequently held outside, but in a shaded area, against the wall of the makeshift laboratory (an abandoned building of the old scientific station) at natural day length (c. 16L:8D) and temperature $\left(c .1-4^{\circ} \mathrm{C}\right)$. As was the case at Marion Island, these 'field-fresh' caterpillars were used for experiments within $24 \mathrm{~h}$ of collection. Owing to the absence of reliable incubation facilities only a single acclimation trial was undertaken. Caterpillars were held at $0{ }^{\circ} \mathrm{C}$ for 7 days by keeping them on melting ice in an insulated container at natural day length. During the acclimation period caterpillars were supplied with fresh filter paper (moistened) and grass cuttings every 3 days.

\subsection{Thermal biology and desiccation resistance}

The full protocols for the work at Marion Island are provided by Klok and Chown (1998). These protocols were followed at Heard Island as closely as possible, with only a few modifications to accommodate the less extensive facilities. For the determination of supercooling points (SCP, or temperature of crystallization) the methods of Klok and Chown (1997, 1998) were followed. The SCPs of individual field-fresh caterpillars, caterpillars starved at $100 \%$ relative humidity for 7 days at ambient temperature outside the laboratory, caterpillars acclimated at $0{ }^{\circ} \mathrm{C}$, field-fresh caterpillars inside $P$. cookii tillers, and field-fresh caterpillars inside moist filter paper were determined. Individual caterpillars (field fresh and $0{ }^{\circ} \mathrm{C}$ acclimated) were placed tightly in pipette tips with a 40 gauge copper-constantan thermocouple inserted between the specimen and the pipette tip wall. For caterpillars inside $P$. cookii tillers or moist filter paper the thermocouples were inserted between the caterpillar and the surrounding grass tissue or moist filter paper. The specimens in the pipette tips were placed in air-filled vials and submerged in a Grant LTC12 waterbath and cooled from $0{ }^{\circ} \mathrm{C}$ at $0.1{ }^{\circ} \mathrm{C} \mathrm{min}{ }^{-1}$. The thermocouples were connected to a Campbell Scientific CR10 datalogger which measured temperatures every second and calculated and logged the mean for each specimen every $15 \mathrm{~s}$. The temperature logged directly prior to the freezing exotherms was noted as the supercooling point (Lee, 1991). Mean SCP was calculated for each experimental group. However, because frequency distributions of SCPs generally revealed a non-normal (and perhaps bimodal, see also Klok and Chown, 1998) distribution of the data, means ( \pm S.E.) were derived for each group (a high and a low group) and the distribution of specimens in the two SCP groups (using $-15^{\circ} \mathrm{C}$ as the threshold), was expressed as the ratio $R=\mathrm{LG} /(\mathrm{HG}+\mathrm{LG})$, where $\mathrm{LG}$ and $\mathrm{HG}$ are the numbers of specimens in each group, respectively (Block, 1982). Single classification analyses of variance (ANOVA) were used for comparisons among islands, or within islands among treatments for each of the low and high groups. In addition, because the bimodality of the data in the Heard Island population was not as clear as for the Marion Island population, the ANOVAs for the among island comparisons were also undertaken with the combined SCP data. 
To determine upper and lower lethal temperatures similar protocols were followed on Marion and Heard Islands. For lower lethal limits, groups of ten caterpillars were placed in $1.5 \mathrm{cc}$ eppendorf vials on a dry strip of filter paper, to absorb any potential condensation, and submerged in the Grant LTC12 waterbath. Caterpillars were kept for a 15 min equilibration period at $0{ }^{\circ} \mathrm{C}$ after which the temperature was lowered at $0.1^{\circ} \mathrm{C} \mathrm{min}{ }^{-1}$ until the first temperature, $-6{ }^{\circ} \mathrm{C}$, was reached. After $1 \mathrm{~h}$, one vial was removed from the bath and the specimens were given $24 \mathrm{~h}$ to recover at laboratory temperature $\left(8 \pm 1^{\circ} \mathrm{C}\right.$ at Heard Island, $2 \pm 0.5^{\circ} \mathrm{C}$ at Marion Island). The temperature was then lowered $1{ }^{\circ} \mathrm{C}$ at $0.1{ }^{\circ} \mathrm{Cmin}^{-1}$, and the above procedure repeated (Worland et al., 1992). This was continued to $-25^{\circ} \mathrm{C}$. After $24 \mathrm{~h}$, caterpillars were assessed for survival and only those with full locomotor function were considered survivors. These survivors were reassessed after seven days. To determine upper lethal temperatures, vials each containing ten caterpillars on $P$. cookii cuttings were warmed at $0.1{ }^{\circ} \mathrm{C} \mathrm{min}^{-1}$ to $30^{\circ} \mathrm{C}$ $\left(25^{\circ} \mathrm{C}\right.$ at Marion Island), where the experiment commenced. Ten caterpillars were removed after $1 \mathrm{~h}$ and the temperature raised by $1{ }^{\circ} \mathrm{C}$ at $0.1^{\circ} \mathrm{Cmin}^{-1}$ and the procedure repeated. This was continued to $40{ }^{\circ} \mathrm{C}\left(43{ }^{\circ} \mathrm{C}\right.$ at Marion Island). Caterpillars were assessed for survival after $24 \mathrm{~h}$ at laboratory temperature, and survivors were reassessed after 7 days.

For the desiccation resistance trials, 40 field-fresh caterpillars were held for $24 \mathrm{~h}$ with access to water only at $8 \pm 1{ }^{\circ} \mathrm{C}\left(2 \pm 0.5^{\circ} \mathrm{C}\right.$ at Marion Island $)$ to allow them to clear their digestive tracts. They were numbered, weighed (to the nearest $0.0001 \mathrm{mg}$ using a Mettler UMT2 electronic microbalance) and placed in desiccation chambers containing silica gel at $0.66 \mathrm{kPa}$ saturation deficit (5\% relative humidity) at $8 \pm 1{ }^{\circ} \mathrm{C}$ and natural day length $\left(2 \pm 0.5^{\circ} \mathrm{C} ; 9 \mathrm{~L}: 15 \mathrm{D}\right.$ at Marion Island). The caterpillars were weighed every $12 \mathrm{~h}$ until $100 \%$ mortality. Mortality was assessed by turning the caterpillars on their backs and the inability to right themselves constituted death. Maximum tolerable water loss (mg), the percentage fresh mass lost (\% FM), time to maximum tolerable water loss (h), and rate of water loss expressed as $\% \mathrm{FM} \mathrm{h}^{-1}$ and $\mathrm{mg} \mathrm{h}^{-1}$ were calculated from the mass recorded at the time interval directly preceding death in each caterpillar. These measures were used because water loss due to cuticular and respiratory transpiration could not be determined separately. The caterpillars produced no frass, therefore we assumed that mass loss was approximately equivalent to incidental and respiratory water loss, with a small effect of substrate loss owing to catabolism. To determine the effects of starvation, the same procedure was followed except that caterpillars were placed in chambers with moistened filter paper to maintain $100 \%$ relative humidity. This experiment was conducted at the same time, and with the same conditions (except for relative humidity) as the desiccation experiment, and the survival of all specimens were checked at the time of death of the last remaining caterpillar in the desiccation experiments. Comparisons among island populations were made using analyses of variance or covariance as appropriate.

\section{Results}

Throughout this section most attention is drawn to the new results for caterpillars on Heard Island (hereafter HI), and comparisons are then made with the population on Marion Island (hereafter MI), the results for which are reported in full by Klok and Chown (1998).

In the supercooling point experiments (Table 2) no caterpillars survived freezing. A single classification ANOVA of the SCPs of the field-fresh caterpillars and those acclimated at $0{ }^{\circ} \mathrm{C}$ indicated that the acclimation treatment had no significant effect on SCP $\left(F_{(1,54)}=3.51, p=0.067\right)$. Frequency distributions of SCPs also indicated that caterpillars in both above groups showed non-normal distributions, that could be considered bimodal when compared with the MI population (see Fig. 1 in Klok and Chown, 1998). These distributions, when divided into high and low groups

Table 2

Summary statistics for the supercooling points (SCP) of Embryonopsis halticella caterpillars and their host, P. cookii, from Heard Island (see text for details)

\begin{tabular}{|c|c|c|c|c|}
\hline $\mathrm{SCP}$ of & Mean \pm S.E. & Minimum & Maximum & $n$ \\
\hline Field fresh caterpillars & $-17.6 \pm 0.9$ & -26.1 & -5.2 & 40 \\
\hline Starved caterpillars & $-15.4 \pm 1.6$ & -25.0 & -4.0 & 20 \\
\hline Caterpillars acclimated at $0^{\circ} \mathrm{C}$ & $-20.5 \pm 1.1$ & -25.1 & -7.3 & 16 \\
\hline Caterpillars within $P$. cookii tillers & $-9.5 \pm 0.7$ & -16.4 & -3.1 & 25 \\
\hline Caterpillars within moist filter paper & $-6.7 \pm 0.5$ & -8.2 & -3.2 & 10 \\
\hline Field fresh P. cookii & $-12.8 \pm 0.7$ & -19.7 & -5.3 & 20 \\
\hline P. cookii containing caterpillars & $-6.7 \pm 0.5$ & -14.6 & -2.5 & 25 \\
\hline Moist filter paper & $-5.2 \pm 0.3$ & -7.4 & -3.4 & 20 \\
\hline
\end{tabular}




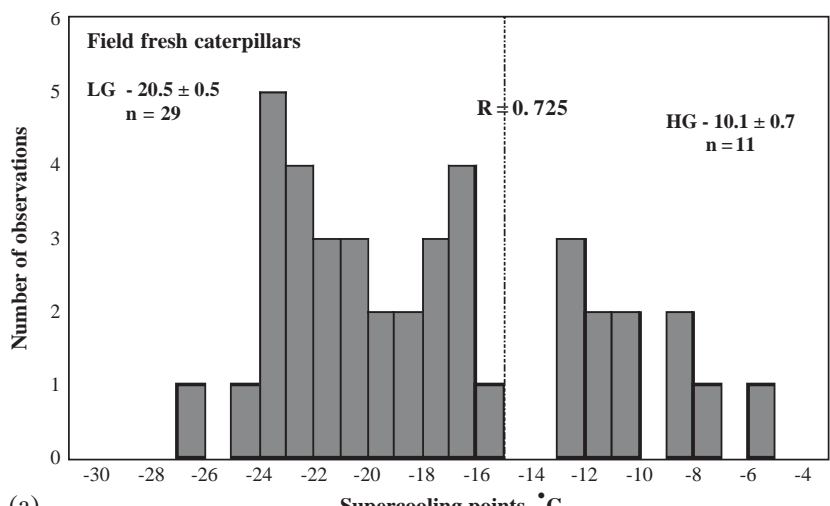

(a)

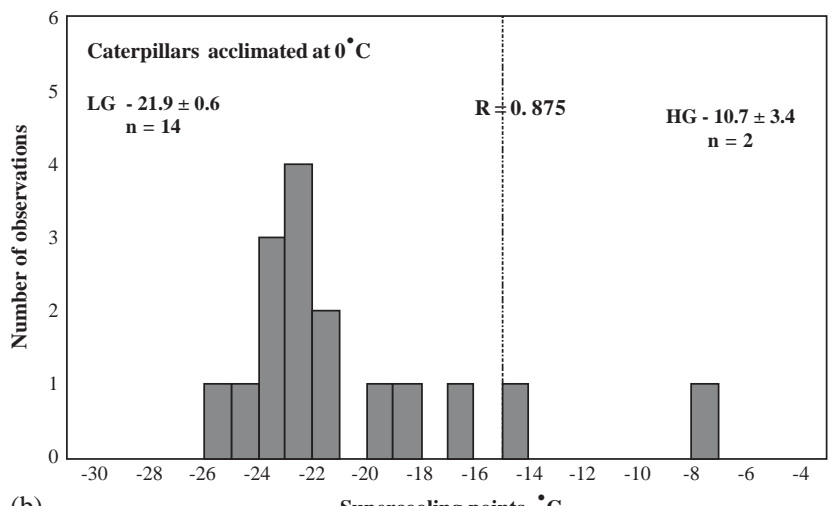

(b)

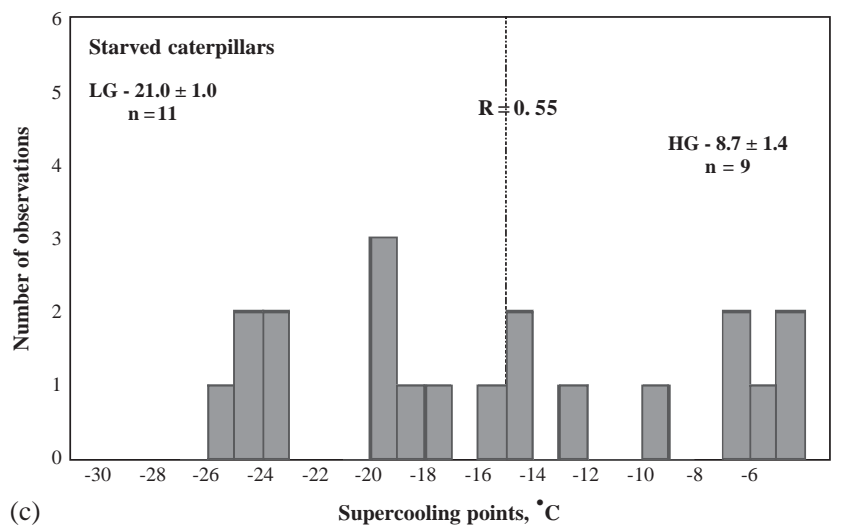

(c)

Supercooling points, ${ }^{\circ} \mathrm{C}$

Fig. 1. Frequency distributions of supercooling points for E. halticella caterpillars from Heard Island: (a) field-fresh caterpillars, (b) caterpillars acclimated at $0{ }^{\circ} \mathrm{C}$, (c) caterpillars starved for 7 days. Means \pm S.E., sample size $(n)$ for the high group (HG) and low group (LG) values and the relationship between these $(R=\mathrm{LG} /(\mathrm{LG}+\mathrm{HG}))$ for each experiment are provided. The division between the $\mathrm{HG}$ and $\mathrm{LG}$ is $-15^{\circ} \mathrm{C}$. See text for further detail.

had similar $R$ values $\left(R_{\mathrm{FF}}=0.725\right.$ and $R_{0^{\circ} \mathrm{C} \text { Accl }}=0.875$; see Fig. 1). There was no difference between the fieldfresh and acclimation groups when high $\left(F_{(1,11)}=0.069\right.$, $p=0.797)$ and low $\left(F_{(1,41)}=2.689, p=0.1087\right)$ group caterpillars were compared. The MI population likewise showed no difference in SCPs between field-fresh caterpillars and those acclimated to $2^{\circ} \mathrm{C}$ (Klok and Chown, 1998). At HI, there was no difference between the SCPs of field-fresh individuals and those that had been starved for 7 days $\left(F_{(1,58)}=1.68, p=0.20\right)$.
Starved caterpillars also showed a somewhat bimodal SCP distribution although their ratio was more balanced between $\mathrm{HG}$ and $\mathrm{LG}(R=0.55$; Fig. 1$)$. Once again this result is very similar to that found at MI, where SCPs did not differ between starved and fed groups. Indeed, these similarities are born out by direct comparisons of the LG and HG SCPs of the populations from each island. In no instances were there significant differences among the MI and HI populations for LG and $\mathrm{HG}$ field-fresh, low temperature acclimated, and starved caterpillars (Table 3). This was also the case for the low temperature acclimated caterpillars when the full distributions were compared. However, when this was done for the field fresh and starved caterpillars, the MI population had significantly lower SCPs than the HI population in both cases (Table 3 ).

As was the case for the MI experiments, on HI SCPs of caterpillars within $P$. cookii, and those of the grass itself, were readily distinguishable during assessments of the SCPs of caterpillars within the grass (Fig. 2). Because of its larger size, and hence larger absolute amount of water, the excised $P$. cookii leaf showed a broader exotherm than the caterpillar, making distinction between caterpillar and grass freezing points relatively easy. Moist filter paper in contact with caterpillars gave similar patterns. On HI, the SCP of the field-fresh $P$. cookii was significantly lower than that of $P$. cookii containing caterpillars (Table 2, $F_{(1,43)}=$ $29.59, p<0.0001)$. Field-fresh caterpillars froze at significantly lower temperatures than did the caterpillars within the $P$. cookii tillers or in contact with moist filter paper, but the latter two groups did not differ significantly $\left(F_{(2,72)}=37.50, p<0.0001\right.$; Tukey's Honest Significant Difference). No significant relationship was found between the freezing point of $P$. cookii and that of the caterpillars $\left(F_{(1,23)}=1.97, p=0.174\right)$, but there was a significant relationship between the freezing point of $P$. cookii and the difference in freezing point of $P$. cookii and the freezing point of the caterpillar (Difference $=6.918+0.622 P$. cookii SCP, $r^{2}=0.188$, $\left.F_{(1,23)}=5.333, p<0.03\right)$. This suggests that the influence of the host on the SCP of the caterpillars becomes more marked at lower temperatures. These results show both similarities and differences to those of the Marion Island population. In general, caterpillars of both populations show an increase in SCP when held within tillers, and the effect of the host becomes more pronounced at low temperatures in both cases. However, the host SCP was much lower on HI than on MI when free of caterpillars, and the effect of caterpillars on the host was stronger on HI than it was on MI (Table 3). Although the high and low group SCPs differed among island populations for the caterpillars within host tillers, the magnitude of these differences was relatively small, and this remained the case when the entire distributions were analysed (Table 3). 
Table 3

Outcomes of the statistical comparisons of supercooling points of several categories of E. halticella caterpillars and their $P$. cookii host plant from Marion Island (autumn 1997) and Heard Island (summer 2000)

\begin{tabular}{|c|c|c|c|c|c|}
\hline \multirow[t]{2}{*}{ Categories } & \multicolumn{2}{|c|}{ Mean SCP \pm S.E. } & \multicolumn{3}{|c|}{ ANOVA } \\
\hline & Marion & Heard & $F$-ratio & $\mathrm{df}$ & $p$ \\
\hline \multicolumn{6}{|l|}{ Low groups } \\
\hline Field fresh & $-20.9 \pm 0.6$ & $-20.5 \pm 0.5$ & 0.933 & 1,50 & 0.339 \\
\hline Low temp. accl. $\left(2^{\circ} \mathrm{C}^{\text {Marion }} ; 0^{\circ} \mathrm{C}^{\text {Heard }}\right)$ & $-20.5 \pm 0.6$ & $-21.9 \pm 0.6$ & 2.485 & 1,28 & 0.126 \\
\hline Starved caterpillars & $-22.1 \pm 0.7$ & $-21.0 \pm 1.0$ & 0.844 & 1,26 & 0.367 \\
\hline Caterpillars within $P$. cookii tillers & $-15.4 \pm 0.1$ & $-16.4 \pm 0.1$ & 75.797 & 1,5 & $<0.0003$ \\
\hline \multicolumn{6}{|l|}{ High groups } \\
\hline Field fresh & $-12.9 \pm 1.2$ & $-10.1 \pm 0.7$ & 2.362 & 1,11 & 0.153 \\
\hline Low temp. accl. $\left(2^{\circ} \mathrm{C}^{\text {Marion }} ; 0^{\circ} \mathrm{C}^{\text {Heard }}\right)$ & $-12.7 \pm 1.0$ & $-10.7 \pm 3.4$ & 0.700 & 1,4 & 0.459 \\
\hline Starved caterpillars & $-11.6 \pm 2.3$ & $-8.7 \pm 1.4$ & 1.199 & 1,10 & 0.299 \\
\hline Caterpillars within $P$. cookii tillers & $-10.7 \pm 0.6$ & $-8.5 \pm 0.5$ & 7.967 & 1,41 & $<0.007$ \\
\hline \multicolumn{6}{|l|}{ Entire distribution } \\
\hline Field fresh & $-20.5 \pm 0.9$ & $-17.6 \pm 0.7$ & 5.856 & 1,63 & 0.018 \\
\hline Low temp. accl. $\left(2^{\circ} \mathrm{C}^{\text {Marion }} ; 0{ }^{\circ} \mathrm{C}^{\text {Heard }}\right)$ & $-19.0 \pm 0.9$ & $-20.5 \pm 1.1$ & 1.141 & 1,34 & 0.293 \\
\hline Starved caterpillars & $-20.5 \pm 1.4$ & $-15.4 \pm 1.4$ & 6.776 & 1,38 & 0.013 \\
\hline Caterpillars within $P$. cookii tillers & $-11.5 \pm 0.6$ & $-9.5 \pm 0.6$ & 4.738 & 1,48 & $<0.035$ \\
\hline Field fresh $P$. cookii & $-9.4 \pm 0.9$ & $-12.8 \pm 0.7$ & 6.602 & 1,38 & $<0.014$ \\
\hline P. cookii containing caterpillars & $-9.3 \pm 0.6$ & $-6.7 \pm 0.5$ & 9.071 & 1,48 & $<0.004$ \\
\hline
\end{tabular}

Due to the bimodality of the SCPs, comparisons were made between low groups and high groups (see text for details).

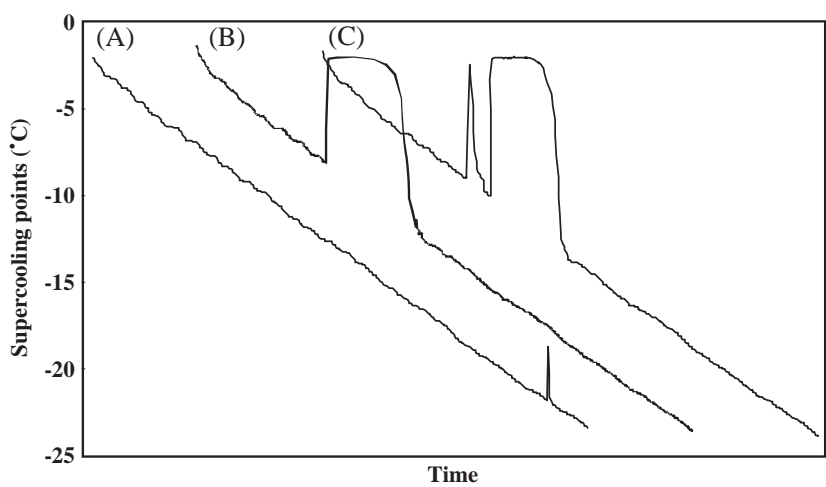

Fig. 2. Three samples of temperature recording traces of supercooling experiments (temperature ramp of $0.1{ }^{\circ} \mathrm{C}$ in each case). Trace A represents the temperature recording of a single $E$. halticella caterpillar. The small peak at the lower end of the trace is the exotherm. Trace B represents the temperature recording for a cutting of $P$. cookii. Note the broadened exotherm. Because the grass cutting is much larger than the caterpillar there is a greater volume of fluid to undergo the phase transition from liquid to solid and, as a result, a greater quantity of latent heat is released over a longer time during the freezing of grass. Trace $\mathrm{C}$ represents the temperature recording of both a cutting of $P$. cookii and an embedded caterpillar. Both the grass and the caterpillar were in contact with the thermocouple. Because of the distinctive exotherms given by the grass and the caterpillar (A and B) the respective supercooling points can readily be distinguished.

In the lower lethal limits experiments caterpillar mortalities on Heard Island corresponded closely to the distributions of the SCP values for field-fresh caterpillars (Fig. 3a). There was a distinct drop in survival from $-12{ }^{\circ} \mathrm{C}$ (although the groups at $-16^{\circ} \mathrm{C}$ only had $40 \%$ mortality) reaching $0 \%$ survival from $-20^{\circ} \mathrm{C}$ onwards. This suggests that over a short timescale there are no prefreeze mortalities in $E$. halticella caterpillars and that the SCP represents their lower lethal temperature. In the determination of upper lethal temperatures, survival dropped markedly above $38^{\circ} \mathrm{C}$ (Fig. 3b). These results could not be compared statistically with those from the MI population. However, the figures indicate that the upper lethal temperatures are virtually identical for both populations, and that LT100 values for lower lethal temperatures are also the same. However, there is some variation in the way that the LT100 values are approached, with the Heard Island individuals having a lower initial survival than Marion Island individuals at the same temperatures.

Summary statistics for maximum tolerable water loss, rate of water loss and time to maximum water loss for the HI population are provided in Table 4. The caterpillars lost approximately a third of their body mass over a large range of survival times. Rate of water loss, maximum tolerable water loss, and time to maximum water loss were significantly related to initial body mass (Table 4). All caterpillars in the starvation experiment were still alive at the end of the desiccation experiment at $175 \mathrm{~h}$. By comparison with the MI population, the HI caterpillars used for the water loss experiments were generally larger $(5.27 \pm 0.77$ vs. $1.43 \pm 0.18 \mathrm{mg}$, respectively; $\left.F_{(1,77)}=19.9, p<0.0001\right)$, perhaps as a consequence of differences in seasonal responses (see Section 4). In consequence, maximum tolerable water loss was greater for the HI population (ANCOVA $F_{(1,73)}=5.127, p<0.027$ ), but so was water loss rate (ANCOVA $F_{(1,73)}=5.00, p<0.028$ ). However, the upshot was that the most important determinant of 

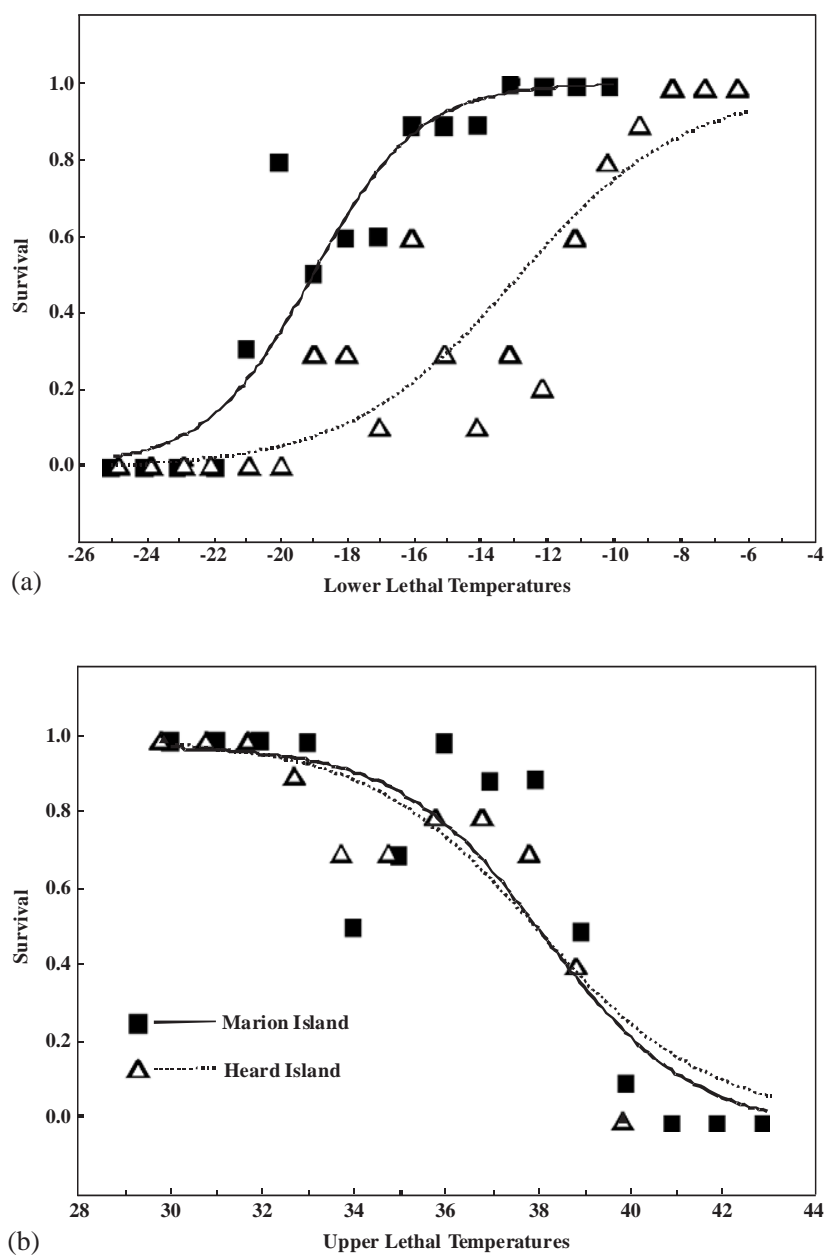

Fig. 3. The decline in survival at a. lower and b. upper lethal temperatures (in ${ }^{\circ} \mathrm{C}$ ) for $E$. halticella caterpillars. The fitted lines are logistic regression curves (all significant at $p<0.05$ ), with the following equations: LLT Heard: Mortality $=\operatorname{EXP}(-5.1156-0.39696 *$ LLT $)$ $\left(1+\operatorname{EXP}\left(-5.1156-0.39696^{*} \mathrm{LLT}\right)\right) ; \quad$ LLT Marion: Mortality $=\mathrm{EXP}$ $(-11.993-0.63047 *$ LLT $) /(1+\operatorname{EXP}(-11.993-0.63047 *$ LLT $)) ; \quad$ ULT Heard: $\quad$ Mortality $=\operatorname{EXP}(-20.301+0.535821 *$ ULT $) /(1+\operatorname{EXP}(-20.301$ $+0.535821 * \mathrm{ULT})) ; \quad$ ULT Marion: Mortality $=\operatorname{EXP}(-23.75+$ $0.622562 * \mathrm{ULT}) /(1+\operatorname{EXP}(-23.75+0.622562 * \mathrm{ULT}))$. desiccation resistance, survival time, did not differ among the populations (ANCOVA $F_{(1,73)}=3.27$, $p=0.075)$. The temperature difference between the trials on the two islands $\left(6^{\circ} \mathrm{C}\right)$ therefore had little effect on survival time (even taking differences in mass of the caterpillars into account).

\section{Discussion}

The cold hardiness strategy of E. halticella on HI appears to be identical to that of the population on MI. Both populations are freeze avoiding and over the short term show no prefreeze mortality. In Bale's (1993, 1996) terminology they can be considered chill tolerant, and perhaps moderately so. Although the investigations of acclimation effects were in no way as extensive on HI as they were on MI, owing to poor laboratory conditions on the former, the low-temperature acclimation trial gave identical results for both populations. Thus, it seems unlikely that acclimatization to the coming winter in the MI population (the work was undertaken in late autumn (April-May) for that population, see Klok and Chown, 1998), but summer acclimatization in the HI population (the experiments were done between December and February) could explain the absence of differences between the populations. It is well known that there is a pronounced cold hardening response by freeze avoiding insects to approaching winter conditions, which is usually accompanied by lowered freezing points and changes in body chemistry (especially upregulation of cryoprotectants) (reviews in Lee and Denlinger, 1991; Chown and Nicolson, 2004). However, the data from the field-fresh and low temperature acclimated populations suggest that both populations maintain substantial cold hardiness irrespective of the season. Of course, a fairer comparison might have been one made between summer-acclimatized individuals

Table 4

Summary statistics for starting mass, maximum tolerable water loss, rate of water loss and time to maximum water loss in the desiccation experiment, and the relationships between initial mass and maximum tolerable mass loss, rate of water loss and survival time, in E. halticella caterpillars from Heard Island

\begin{tabular}{lccc}
\hline Variable & Mean \pm S.E. & Minimum & Maximum \\
\hline Starting mass (mg) & $5.2698 \pm 0.7681$ & 0.3690 & 13.4980 \\
Maximum tolerable loss (mg) & $1.8816 \pm 0.2901$ & 0.0320 & 4.6330 \\
Maximum tolerable loss (\%) & $30.56 \pm 1.37$ & 8.67 & 45.83 \\
Rate $\left(\mathrm{mg} \mathrm{h}^{-1}\right)$ & $0.0359 \pm 0.0115$ & 0.0034 & 0.4300 \\
Rate $\left(\% \mathrm{~h}^{-1}\right)$ & $1.22 \pm 0.25$ & 0.19 & 6.54 \\
Time $(\mathrm{h})$ & $73.95 \pm 10.04$ & 6.0 & 37 \\
Regression analyses & & & 37 \\
Mass loss $=0.35-0.072$ starting mass & $r^{2}=0.967$ & $p<0.0001$ & 37 \\
Rate $=0.0173+0.003$ starting mass & $r^{2}=0.057$ & $p<0.153$ & $F_{(1,35)}=1035.3$ \\
Time $=16.69+10.3$ starting mass & $r^{2}=0.694$ & $p<0.0001$ & $F_{(1,35)}=2.1$ \\
\end{tabular}


from both islands. Although such data are not available for Marion Island, the SCPs of caterpillars from the $15{ }^{\circ} \mathrm{C}$ acclimation trial on MI did not differ from fieldfresh individuals on HI (All SCP values: $F_{(1,58)}=1.72$, $p=0.195$, mean \pm S.E. MI: $-15.5 \pm 1.4^{\circ} \mathrm{C}$, HI: $-17.6 \pm$ $0.9^{\circ} \mathrm{C}$; High group values: $F_{(1,19)}=0.0017, p=0.968$, MI: $-10.1 \pm 0.7^{\circ} \mathrm{C}, \mathrm{HI}:-10.1 \pm 0.7^{\circ} \mathrm{C}$; Low group values: $F_{(1,37)}=0.0273, p=0.605, \mathrm{MI}:-21.0 \pm 0.9^{\circ} \mathrm{C}$ HI: $-20.5 \pm 0.5^{\circ} \mathrm{C}$ ). However, these results belie the movement of individuals between the high and low groups. In this particular instance for the $15^{\circ} \mathrm{C}$ acclimation trial on $\mathrm{MI}$, there were 10 individuals in each group, whereas in the field-fresh individuals on HI, there were 11 individuals in the high group and 29 in the low group. This suggests that if there were to be pronounced differences between the populations, they would be found in the proportion of individuals in the high and low groups, given that there is such malleability in movement between the groups (Klok and Chown, 1998). The analyses of the full SCP distributions and those of the high and low groups for the field fresh and starved caterpillars lend support to this idea. For both the field fresh and starved caterpillars the high and low groups did not differ between the populations, but when the entire distributions were analyzed the populations differed substantially, mostly as a consequence of larger numbers of individuals in the high group on Heard Island (compare Fig. 1. here with Fig. 1 of Klok and Chown, 1998).

Acknowledging that the two studies were undertaken at different times of the year, and that the acclimation trials were not as sophisticated as they might have been at Heard Island, these results nonetheless suggest that differences between the populations are mostly a consequence of phenotypic plasticity, rather than strict adaptation. This is likewise reflected in the differences in the shape of the lower lethal temperature curve (Fig. 3a). It is also in keeping with findings for weevils across the two islands (Klok and Chown, 2003), with large-scale latitudinal variation in low temperature recovery times in D. melanogaster, which appear to be a consequence of plasticity rather than adaptation (Ayrinhac et al., 2004), and with other traits in the latter species (Hoffmann et al., 2001, 2005).

Although bimodality of SCPs in the HI caterpillar population was not as clear as that on MI, the distributions were distinctly non-normal, and certainly resembled the bimodality in the MI population. Quite why there should be animals with 'high' and those with 'low' SCPs has long been a subject of contention in the literature (Baust and Rojas, 1985; Parish and Bale, 1990; Sømme and Block, 1991), and is thought by some to be a consequence of gut evacuation and dehydration. By contrast, based on little difference between the SCPs of starved and fed individuals on MI, as was found again for the HI population, and on the habit of the caterpillars of retaining food in their guts for long periods (Crafford and Scholtz, 1986), Klok and Chown (1998) implied that the SCP division into two groups might represent some kind of physiological bet-hedging strategy. In the context of the unpredictable and generally cold climates of the sub-Antarctic (Sinclair et al., 2003), such a strategy does seem plausible (see also Bale et al., 2001). However, Klok and Chown (1998) also noted that the cold hardiness of the caterpillars was considerably better developed than might be expected from microclimates at MI (see their Tables 1 and 7, and Table 1 here), and attributed this considerable cold hardiness to the accumulation of solutes that might assist in making this species so highly desiccation resistant. Although bet-hedging seems unlikely given the latter, Sinclair and Chown (2002) demonstrated that the haemloymph osmolality of $E$. halticella (mean: $358-370 \mathrm{mOsm}$ ) is no different to that of most other insects, and questioned the interpretation provided by Klok and Chown (1998), leaving the problem of considerable cold hardiness in E. halticella unresolved.

The present data from HI go some way to providing a solution. As was the case on MI, the SCPs (and hence the lower lethal temperatures) of the caterpillars were substantially higher when caterpillars were ensheathed within their host leaves. Moreover, it is clear that the lower the temperature at which the host freezes, the more likely it is to inoculate freezing in the caterpillars in both populations, with equivalence at approximately $-10^{\circ} \mathrm{C}$ for the HI population. Thus, caterpillars within leaves freeze at approximately $-9.5^{\circ} \mathrm{C}$ at $\mathrm{HI}$, and are very likely inoculated by their hosts at temperatures below this value. These temperatures are reasonably close to the microclimatic limits found at Heard Island. Although long-term climatic data are not available, what records there are demonstrate that absolute minimum air temperatures can reach $-8.4^{\circ} \mathrm{C}$ in the summer months, and can decline to $-5.9^{\circ} \mathrm{C}$ even within P. cookii tussocks (Table 1). From this perspective, the tolerance limits of E. halticella (Table 2) seem readily explicable, given that they closely match those of the extremes of their natural environment, i.e. the likely situation within $P$. cookii tillers.

If it is presumed that the physiological tolerances of E. halticella are conservative, as seems likely given similarities in cold hardiness, upper lethal limits and desiccation resistance of the MI and HI populations, then the extreme cold hardiness of the population at MI might simply be a consequence of physiological inertia (Huey et al. (2003) provide a discussion of drive vs. inertia in evolution), or a lack of change in their tolerances since arriving at the island (there is no evidence for the occurrence of $P$. cookii at Marion Island during the last glacial maximum, 18,000 \pm 2000 years before present, Scott, 1985). Such an explanation based on inertia presumes that the population of 
E. halticella on MI is more derived than the one on HI. Although no phylogeographic data for this species are available, geological and biogeographic studies indicate that this is likely to be the case. Not only is Marion Island geologically much younger $(<0.5 \mathrm{Ma})$ than the islands on the Kerguelen Plateau ( $>40 \mathrm{Ma}$ ) (Heard and Kerguelen) (LeMasurier and Thomson, 1990; McDougall et al., 2001; Wallace et al., 2002), but its biota is also clearly derived from that group (Kuschel and Chown, 1995; Greve et al., 2005).

Thus, it seems likely that the extreme cold hardiness of the population on MI is a consequence of physiological inertia, rather than of the extreme desiccation resistance of the species. Although this considerable desiccation resistance is not in question, and is plausibly a response to high saturation deficits and a lack of boundary conditions owing to high winds (Klok and Chown, 1998 provide a comprehensive explanation), it now seems clear that it has had little effect on the cold hardiness of the caterpillars, and the two traits are probably not as closely linked as was suggested by Klok and Chown (1998). The bet-hedging strategy, whereby individuals are capable of altering their SCPs, thus remains plausible, but to gain support it would need considerably greater exploration in the context of seasonal variation at either of the islands, as has been done for several other insects (e.g. Chen et al., 1991; Sinclair, 1997; Bale et al., 2000, 2001). The question of the extent of physiological inertia also deserves further scrutiny to ascertain how common it is in other traits in this species. It certainly does not appear to extend to life history traits in E. halticella, given that the population at MI appears to have overlapping generations, whilst the one at HI appears to be more synchronized. Nonetheless, it may be characteristic of other physiological variables such as metabolic rates and critical thermal limits.

In conclusion, this study has demonstrated that there is considerable inertia in cold hardiness, upper lethal limits and desiccation resistance of populations of $E$. halticella across two islands that differ considerably in their climates. This finding is in keeping with at least one other group in the region (Klok and Chown, 2003), and is similar to recent findings for $D$. melanogaster (Hoffmann et al., 2001; Ayrinhac et al., 2004), where population differences are largely a consequence of phenotypic plasticity (but see also Hoffmann et al., 2005). The prevalence of such a lack of adaptive geographic variation at the population level needs to be more widely explored. It is in keeping with several models of the way in which limits to species ranges are set (which presume that gene flow reduces adaptive differences between populations-review in Butlin et al., 2003), and also suggests that phenotypic plasticity plays an important role by enabling populations to survive better under marginal conditions (see also Watson and
Hoffmann, 1996; Hoffmann and Parsons, 1997; Klok and Chown, 2003).

\section{Acknowledgments}

Dana Bergstrom and Kate Kiefer provided assistance in Australia and at Heard Island, and Andrew Lock, Dale Main, and Karl Rollings provided support in the field at Heard Island. Dana Bergstrom and Tore Pedersen (Australian Antarctic Division), and Doug Shepherd and Malcolm Riley (Bureau of Meteorology, Hobart) provided microclimatic and climatic data for Heard Island. Brent Sinclair and two anonymous referees are thanked for useful comments on a previous draft of the paper. Our work at Marion Island is supported by the USAID Capacity Building Programme for Climate Change Research and the South African National Antarctic Programme through the Department of Environmental Affairs \& Tourism, and at Heard Island by the Australian Antarctic Division (ASAC Project No. 1191). This is a contribution to the SCAR EBA programme.

\section{References}

Addo-Bediako, A., Chown, S.L., Gaston, K.J., 2000. Thermal tolerance, climatic variability and latitude. Proceedings of the Royal Society of London B 267, 739-745.

Addo-Bediako, A., Chown, S.L., Gaston, K.J., 2002. Metabolic cold adaptation in insects: a large-scale perspective. Functional Ecology $16,332-338$.

Ayrinhac, A., Debat, V., Gibert, P., Kister, A.-G., Legout, H., Moreteau, B., Vergilino, R., David, J.R., 2004. Cold adaptation in geographical populations of Drosophila melanogaster: phenotypic plasticity is more important than genetic variability. Functional Ecology 18, 700-706.

Bale, J.S., 1993. Classes of insect cold hardiness. Functional Ecology 7, 751-753.

Bale, J.S., 1996. Insect cold hardiness: a matter of life and death. European Journal of Entomology 93, 369-382.

Bale, J.S., Block, W., Worland, M.R., 2000. Thermal tolerance and acclimation response of larvae of the sub-Antarctic beetle Hydromedion sparsutum (Coleoptera: Perimylopidae). Polar Biology $23,77-84$

Bale, J.S., Worland, M.R., Block, W., 2001. Effects of summer frost exposures on the cold tolerance strategy of a sub-Antarctic beetle. Journal of Insect Physiology 47, 1161-1167.

Bartholomew, G.A., 1987. Interspecific comparison as a tool for ecological physiologists. In: Feder, M.E., Bennett, A.F., Burggren, W., Huey, R.B. (Eds.), New Directions in Ecological Physiology. Cambridge University Press, Cambridge, pp. 11-37.

Baust, J.G., Rojas, R.R., 1985. Insect cold hardiness: facts and fancy. Journal of Insect Physiology 31, 755-759.

Berrigan, D., Hoffmann, A.A., 1998. Correlations between measures of heat resistance and acclimation in two species of Drosophila and their hybrids. Biological Journal of the Linnean Society 64, 449-462.

Block, W., 1982. Supercooling points of insects and mites on the Antarctic Peninsula. Ecological Entomology 7, 1-8. 
Butlin, R.K., Bridle, J.R., Kawata, M., 2003. Genetics and the boundaries of species' distributions. In: Blackburn, T.M., Gaston, K.J. (Eds.), Macroecology: Concepts and Consequences. Blackwell Science, Oxford, pp. 274-295.

Chen, C.-P., Denlinger, D.L., Lee, R.E., 1991. Seasonal variation in generation time, diapause and cold hardiness in a central Ohio population of the flesh fly, Sarcophaga bullata. Ecological Entomology 16, 155-162.

Chown, S.L., 1997. Thermal sensitivity of oxygen uptake of Diptera from sub-Antarctic South Georgia and Marion Island. Polar Biology 17, 81-86.

Chown, S.L., 2001. Physiological variation in insects: hierarchical levels and implications. Journal of Insect Physiology 47, 649-660.

Chown, S.L., Crafford, J.E., 1992. Microhabitat temperatures at Marion Island $\left(46^{\circ} 54^{\prime} \mathrm{S} 37^{\circ} 45^{\prime} \mathrm{E}\right)$. South African Journal of Antarctic Research 22, 51-58.

Chown, S.L., Klok, C.J., 2003. Water balance characteristics respond to changes in body size in sub-Antarctic weevils. Physiological and Biochemical Zoology 76, 634-643.

Chown, S.L., Nicolson, S.W., 2004. Insect Physiological Ecology. Mechanisms and Patterns. Oxford University Press, Oxford.

Chown, S.L., Van Der Merwe, M., Smith, V.R., 1997. The influence of habitat and altitude on oxygen uptake in sub-antarctic weevils. Physiological Zoology 70, 116-124.

Chown, S.L., Gaston, K.J., Robinson, D.J., 2004. Macrophysiology: large-scale patterns in physiological traits and their ecological implications. Functional Ecology 18, 159-167.

Crafford, J.E., Scholtz, C.H., 1986. Impact of Embryonopsis halticella Eaton larvae (Lepidoptera: Yponomeutidae) feeding in Marion Island tussock grassland. Polar Biology 6, 191-196.

Csada, R.D., James, P.C., Espie, R.H.M., 1996. The "file drawer problem" of non-significant results: does it apply to biological research? Oikos 76, 591-593.

Gaston, K.J., Reavey, D., Valladares, G.R., 1991. Changes in feeding habit as caterpillars grow. Ecological Entomology 16, 339-344.

Gibbs, A., Mousseau, T.A., Crowe, J.H., 1991. Genetic and acclimatory variation in biophysical properties of insect cuticle lipids. Proceedings of the National Academy of Sciences of the USA $88,7257-7260$.

Gibert, P., Huey, R.B., 2001. Chill-coma temperature in Drosophila: effects of developmental temperature, latitude, and phylogeny. Physiological and Biochemical Zoology 74, 429-434.

Greve, M., Gremmen, N.J.M., Gaston, K.J., Chown, S.L., 2005. Nestedness of Southern Ocean island biotas: ecological perspectives on a biogeographic conundrum. Journal of Biogeography 32, $155-168$.

Hoffmann, A.A., Parsons, P.A., 1989. An integrated approach to environmental stress tolerance and life-history variation: desiccation tolerance in Drosophila. Biological Journal of the Linnean Society $37,117-136$.

Hoffmann, A.A., Parsons, P.A., 1997. Extreme Environmental Change and Evolution. Cambridge University Press, Cambridge.

Hoffmann, A.A., Hallas, R., Sinclair, C., Mitrovski, P., 2001. Levels of variation in stress resistance in Drosophila among strains, local populations, and geographic regions: patterns for desiccation, starvation, cold resistance, and associated traits. Evolution 55, $1621-1630$

Hoffmann, A.A., Anderson, A., Hallas, R., 2002. Opposing clines for high and low temperature resistance in Drosophila melanogaster. Ecology Letters 5, 614-618.

Hoffmann, A.A., Shirriffs, J., Scott, M., 2005. Relative importance of plastic versus genetic factors in adaptive differentiation: geographical variation for stress resistance in Drosophila melanogaster from eastern Australia. Functional Ecology 19 in press.

Honêk, A., 1996. Geographical variation in thermal requirements for insect development. European Journal of Entomology 93, 303-312.
Huey, R.B., Hertz, P.E., Sinervo, B., 2003. Behavioral drive versus behavioral inertia in evolution: a null model approach. American Naturalist 161, 357-366.

Juliano, S.A., 1986. Resistance to desiccation and starvation of two species of Brachinus (Coleoptera: Carabidae) from southeastern Arizona. Canadian Journal of Zoology 64, 73-80.

Kingsolver, J.G., Huey, R.B., 1998. Evolutionary analyses of morphological and physiological plasticity in thermally variable environments. American Zoologist 38, 545-560.

Klok, C.J., Chown, S.L., 1997. Critical thermal limits, temperature tolerance and water balance of a sub-Antarctic caterpillar, Pringleophaga marioni Viette (Lepidoptera: Tineidae). Journal of Insect Physiology 43, 685-694.

Klok, C.J., Chown, S.L., 1998. Interactions between desiccation resistance, host-plant contact and the thermal biology of a leafdwelling sub-Antarctic caterpillar, Embryonopsis halticella (Lepidoptera: Yponomeutidae). Journal of Insect Physiology 44, 615-628.

Klok, C.J., Chown, S.L., 2003. Resistance to temperature extremes in sub-Antarctic weevils: interspecific variation, population differentiation and acclimation. Biological Journal of the Linnean Society 78, 401-414.

Knox, G.A., 1994. The Biology of the Southern Ocean. Cambridge University Press, Cambridge.

Kuschel, G., Chown, S.L., 1995. Phylogeny and systematics of the Ectemnorhinus-group of genera (Insecta: Coleoptera). Invertebrate Taxonomy 9, 841-863.

Lee, R.E., 1991. Principles of insect low temperature tolerance. In: Lee, R.E., Denlinger, D.L. (Eds.), Insects at Low Temperature. Chapman \& Hall, London, pp. 17-46.

Lee, R.E., Denlinger, D.L. (Eds.), 1991, Insects at Low Temperature. Chapman \& Hall, New York.

LeMasurier, W.E., Thomson, J.W., 1990. Volcanoes of the Antarctic Plate and Southern Oceans. American Geophysical Union, Washington.

Massion, D.D., 1983. An altitudinal comparison of water and metabolic relations in two acridid grasshoppers (Orthoptera). Comparative Biochemistry and Physiology A 74, 101-105.

McDougall, I., Verwoerd, W., Chevallier, L., 2001. K-Ar geochronology of Marion Island, Southern Ocean. Geological Magazine 138, 1-17.

Nylund, L., 1991. Metabolic rates of Calathus melanocephalus (L.) (Coleoptera, Carabidae) from alpine and lowland habitats (Jeloy and Finse, Norway and Drenthe, The Netherlands). Comparative Biochemistry and Physiology A 100, 853-862.

Parish, W.E.G., Bale, J.S., 1990. The effect of feeding and gut content on supercooling in larvae of Pieris brassicae. Cryoletters 11, 67-74.

Parsons, P.A., 1977. Resistance to cold temperature stress in populations of Drosophila melanogaster and D. simulans. Australian Journal of Zoology 25, 693-698.

Schultz, T.D., Quinlan, M.C., Hadley, N.F., 1992. Preferred body temperature, metabolic physiology, and water balance of adult Cicindela longilabris: a comparison of populations from boreal habitats and climatic refugia. Physiological Zoology 65, 226-242.

Schulze, B.R., 1971. The climate of Marion Island. In: van Zinderen Bakker, E.M., Winterbottom, J.M., Dyer, R.A. (Eds.), Marion and Prince Edward Islands. Report on the South African Biological and Geological Expedition 1965-1966. A. A. Balkema, Cape Town, pp. 16-31.

Scott, L., 1985. Palynological indications of the Quaternary vegetation history of Marion Island (sub-Antarctic). Journal of Biogeography $12,413-431$.

Sinclair, B.J., 1997. Seasonal variation in freezing tolerance of the New Zealand alpine cockroach Celatoblatta quinquemaculata. Ecological Entomology 22, 462-467.

Sinclair, B.J., Chown, S.L., 2002. Haemolymph osmolality and thermal hysteresis activity in 17 species of arthropods from subAntarctic Marion Island. Polar Biology 25, 928-933. 
Sinclair, B.J., Addo-Bediako, A., Chown, S.L., 2003. Climatic variability and the evolution of insect freeze tolerance. Biological Reviews 78, 181-195.

Smith, V.R., 2002. Climate change in the sub-Antarctic: an illustration from Marion Island. Climatic Change 52, 345-357.

Sømme, L., Block, W., 1991. Adaptations to alpine and polar environments. In: Lee, R.E., Denlinger, D.L. (Eds.), Insects at Low Temperature. Chapman \& Hall, London, pp. 318-359.

Spicer, J.I., Gaston, K.J., 1999. Physiological Diversity and its Ecological Implications. Blackwell Science, Oxford.

Todd, C.M., 1997. Respiratory metabolism in two species of carabid beetle from the sub-Antarctic island of South Georgia. Polar Biology 18, 166-171.

Todd, C.M., Block, W., 1997. Responses to desiccation in four coleopterans from sub-Antarctic South Georgia. Journal of Insect Physiology 43, 905-913. van der Merwe, M., Chown, S.L., Smith, V.R., 1997. Thermal tolerance limits in six weevil species from sub-Antarctic Marion Island. Polar Biology 18, 331-336.

Wallace, P.J., Frey, F.A., Weis, D., Coffin, M.F., 2002. Origin and evolution of the Kerguelen Plateau, Broken Ridge and Kerguelen Archipelago, editorial. Journal of Petrology 43, 1105-1108.

Watson, M.J.O., Hoffmann, A.A., 1996. Acclimation, cross-generation effects, and the response to selection for increased cold resistance in Drosophila. Evolution 50, 1182-1192.

Williams, J.B., Shorthouse, J.D., Lee, R.E., 2002. Extreme resistance to desiccation and microclimate-related differences in cold-hardiness of gall wasps (Hymenoptera: Cynipidae) overwintering on roses in southern Canada. Journal of Experimental Biology 205, 2115-2124.

Worland, R., Block, W., Rothery, P., 1992. Survival of sub-zero temperatures by two South Georgian beetles (Coleoptera, Perimylopidae). Polar Biology 11, 607-613. 